\title{
THE ROLE OF THE MINERAL WATER FOR THE DEVELOPMENT OF THE DEVIN, BULGARIA STUDY AREA AS A TOURIST DESTINATION
}

\author{
DOI: https://doi.org/10.18509/GBP210163k \\ UDC: 338.483.11:553.7(497.2) \\ 338.487:339.133(497.2)"2007/2019”
}

\author{
Valentin Kotsakov \\ Geography of Tourism Department, Faculty of Geology and Geography, Sofia University \\ "St. Kliment Ohridski", Bulgaria
}

\begin{abstract}
The hectic daily life, the stress at work, the noise in the urban environment, the polluted air of the megacities and other harmful factors accompanying the civilized world are some of the main reasons for reduction the immunity and health status of the population. The introduction of new technologies related to all-day work in front of computer monitors dooms workers to permanent immobilization, unlocking a chain of health problems. These problems include overweight, a significant increase in the number of diabetes mellitus among adults and children, continuous rejuvenation of hypertension, cardiovascular and cerebrovascular accidents. There is more and more talk about "burn out" - a syndrome associated with excessive mental exhaustion. The listed factors lead to an increase in the morbidity of the population.

The solution to some of the questions is in the skillful use of natural healing factors in balneo-climatic and climatic health resorts for the healing of the human body. In recent years, there is a "boom" in the spa and wellness areas in the tourism industry. These areas include the use of climatic factors in combination with hydro, balneo and peloid therapies for the prevention and prophylaxis of chronic diseases, in combination with training in healthy eating. This complex must include programs with a specific motor regime, consistent with the health status of the tourists.

Nowadays, the goal is to return the mankind to the natural healing factors that have been used since ancient times to the present day to heal the body. The issue of taking a person out of the everyday tense and stressful environment, containing various harmful substances, and sending the humans to a calm, ecologically clean and healthy environment is becoming more and more topical. This can be achieved by actively targeting the climatic and spa resorts with specific climatic characteristics - a high percentage of sunshine; low to missing fogs; air rich in light negative ions and phytoncides; natural thermal mineral waters, successfully applied for drinking, external, inhalation and other types of balneotherapy, etc.

Spa treatment affects the human body for a period of 3 to 6 months. The annual conduct of complex climate and balneotherapy in some chronic diseases of the internal organs, leads to dilution of their exacerbations and, accordingly, to a reduction of hospitalizations of patients.

The key to overcoming the above problems is in the rational use of natural healing factors for health prevention and prevention of chronic diseases. The goal is to create a better health culture for exercise, nutrition, alternating active work and rest.
\end{abstract}

Keywords: Balneology, Mineral water, Climatotherapy, Hydrotherapy, SPA and Wellness 


\section{INTRODUCTION}

The importance of health is the most important think of the tourism, as the recreation and development of the physical and mental strength of tourists is the main goal for them to undertake a tourist trip. That is why for the tourist himself too often the priority is the health significance, which affects him directly and personally. In turn, the health significance is divided into healing (known since the ancient times) and prophylactic (typical of most modern types of tourism). A healing effect is when it comes to the treatment of already manifested diseases and complaints, and a prophylactic one - when the attention is focused on achieving a general healing effect or the prevention of certain diseases. The global trend is to increase the relative share of prevention at the expense of treatment. This is primarily due to the increased health culture and the creation of lasting health habits in the population and society as a whole. Usually the healing and prophylactic significance of tourism is associated with a certain type of it - balneotherapy or balneological tourism, based primarily on the presence of mineral waters, healing mud, lye and others [1].

At the end of the 16th century, the interest in the healing effect of the mineral waters was revived, which grew into a boom in the development of the resort business near the healing mineral springs in the 19th century. As Slaveykov [2] points out, at the beginning of the 21st century, tourism is already a mass phenomenon, and the tourism business is developing rapidly, because in many countries huge investments are directed to it.

The balneo-sanatorium business in Bulgaria arose and developed on the basis of mineral waters. The treatment with the use of mineral waters in our lands has an ancient and rich history.

In recent decades, the need for spa treatment and prevention worldwide is growing. As a result of the changed structure of morbidity and frequency of some socially significant diseases, due to overexertion and nervous fatigue, more and more importance is given to the application of resort factors. Modern pharmacological agents cannot always restore the altered reactivity of the human body and normalize a number of regulatory mechanisms altered by the modern way of life.

The increase of these diseases, which are beneficially affected by the action of the balneoclimatic factors, with which both primary and secondary prophylaxis is carried out, forms a great potential for the search for balneo-sanatorium treatment.

The analysis of the health and demographic condition of the population and the forecasts for the coming years give grounds to expect an increase in the health needs of the citizens due to the aging population and the wide spread of chronic diseases requiring an expanded volume of diagnostic, treatment and rehabilitation procedures. The negative trends are the result of insufficiently effective promotion and prevention activities. [3]

The municipality of Devin, that is part of this analysis, has prospects to take its rightful place on the tourist map of Europe, with the emphasis on offering spa tourism.

\section{DEVIN, BULGARIA}

The Municipality of Devin represents $17.83 \%$ of the territory of the District of Smolyan (Fig. 1). The population is 12,097 inhabitants, of which 6,527 live in the town of Devin (54\%). The town of Devin is located 710 meters above sea level in the Rhodope Mountains and it combines diverse terrain, picturesque nature, mild climate and the presence of mineral springs in small. Devin is situated $220 \mathrm{~km}$ away from Sofia, $45 \mathrm{~km}$ from Smolyan and $35 \mathrm{~km}$ from the mountain ski tourist resort "Pamporovo". 


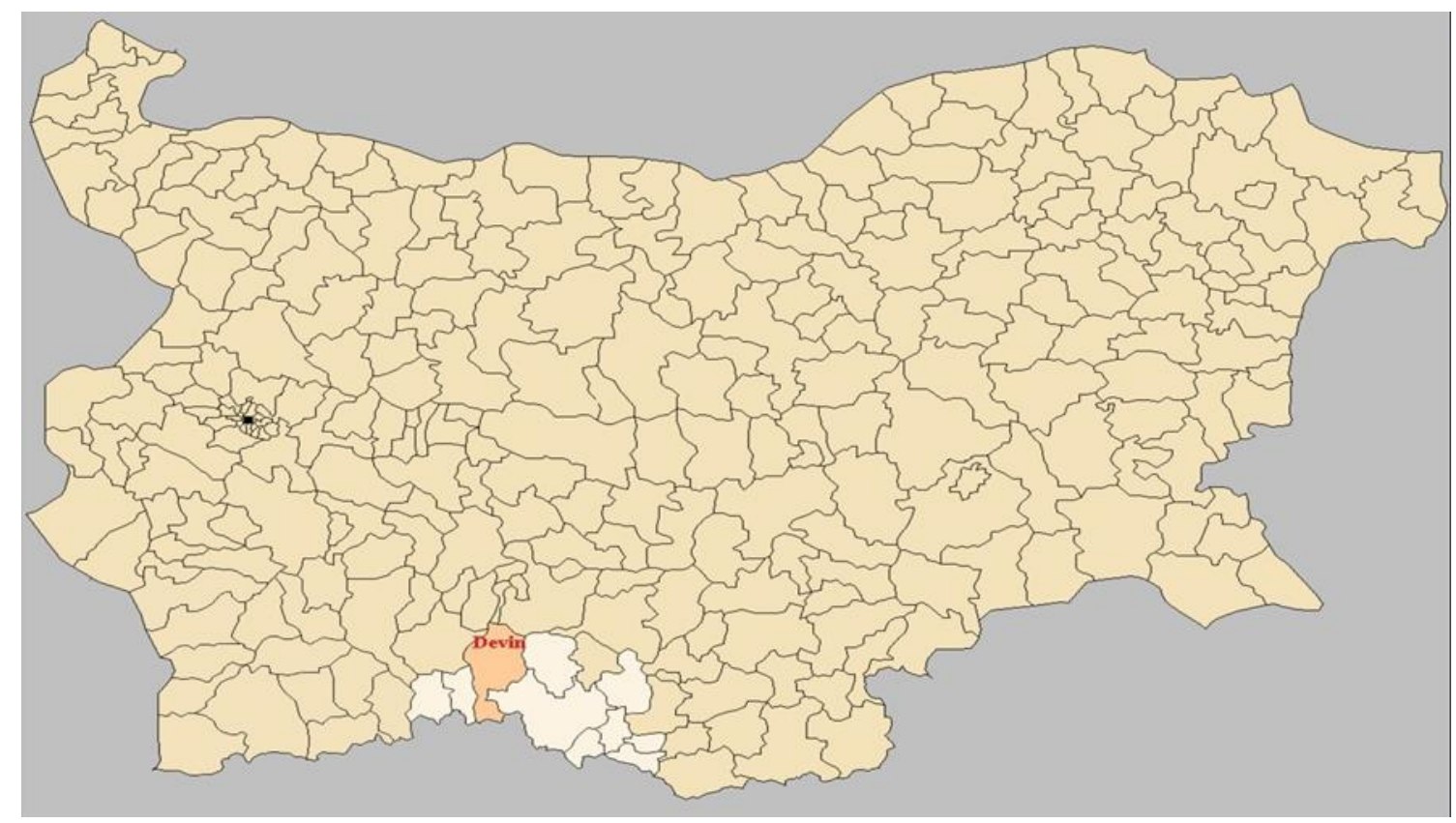

Figure 1. The municipality of Devin on the map of Bulgaria

There are many and diverse natural resources situated on the territory of the municipality of Devin. Many of them are not popularized and accessible for mass tourism. The relief of the municipality of Devin is typically mountainous and has the characteristic features of this part of the Rhodopes - very steep and even inaccessible slopes, deep ravines, and the ridges - sloping to steep. There is a huge difference in altitude - from $420 \mathrm{~m}$ below the sea level of Vacha Dam to 2,091 m on Golyam Persenk Peak. The diverse rock composition has led to the formation of a number of natural phenomena: deep gorges, caves, rock formations and others. Given the horizontal and vertical division and easy possibility of mountain ridges, as well as the presence of numerous natural landmarks, the area is suitable for practicing route-cognitive and sports tourism - orienteering, mountain biking, motocross and more. Devin's climate is transitional-continental, lowland, tempered by its southern geographical location in the country.

The average annual air temperature is $10.5^{\circ} \mathrm{C}$, with an average January - minus $1.5^{\circ} \mathrm{C}$, and in July $-19^{\circ} \mathrm{C}$. Summer is warm but not hot, winter is mild as spring occurs on March 25 , and warm and sunny autumn lasts until November 10. The clouds are moderate; the fog is light and the duration of sunshine in the Rhodopes and in particular in Devin is nearly 260 days a year.

The average annual rainfall is $687 \mathrm{~mm}$, and the snow cover lasts for an average of 55 days during the cold season. These favorable climatic indicators, the clean mountain air, the possibility for daily stay in the higher surroundings provide conditions for fruitful climatotherapy and prevention, for complete recreation and for complex conducting of highly effective balneo-climatotherapy.

Tourist attractions are very important for the sustainable development of any destination, because they give a final end to the stay of tourists. According to Kotler [4] customers are currently in a situation where they have to choose between different experiences and not between different product characteristics. Butler [5] has the opinion that tourist attractions are not endless and eternal, but should be considered and treated as a limited and possibly non-renewable resource. Then they could be more carefully protected and preserved. Due to the many mineral springs, on the territory of the municipality of Devin 
there are several outdoor pools: "Struilitsa", "Orpheus" and water park "Persenk", and a municipal swimming pool from 2020. Another main attraction for mass tourism is the Devil's Throat Cave.

Anthropogenic resources on the territory of the municipality of Devin are a big problem because most of the existing ones have not been turned into assets for tourism, in fact they are not included in the tourist offer, and most of them are in poor condition and need urgent measures for storage and conservation.

Human resources are also a major obstacle to tourism development. The growing need for qualified specialists for the development of the sector requires the conduct of specialized studies and targeted efforts for the development of human capital. On the one hand, this will lead to an increase in the quality of the offered tourist product and growth in the sector, and on the other hand - it could become a prerequisite for limiting the migration of young and qualified staff from the territory of the municipality of Devin. Migration is one of the reasons for the deteriorating age structure of the population in the municipality.

The municipality of Devin still does not have a tourist information center, although according to the number of overnights [6], Devin municipality is a tourist developed municipality.

According to Marinov et al. [7], tourism can be one of the main factors for economic growth.

\section{THE MINRAL WATER AND THE TOURISM IN DEVIN}

The municipality of Devin is a real treasure trove of water resources. It is full of karst springs, rivers and dams, but its great wealth are mineral springs with temperatures between $16^{\circ} \mathrm{C}$ and $76^{\circ} \mathrm{C}$. Here are the healing Bedenski bani near the village of Beden. The water is hot, with a temperature of $74-76^{\circ} \mathrm{C}$, with a significant flow rate, low mineralized, hydrocarbonate-sulphate-sodium, silicon, moderately fluorine, with $\mathrm{pH} 6.9$ and is suitable for external balneotherapy. In the town of Devin there is a large spring with soft mineral water with excellent table properties, well known abroad, and in the village of Mihalkovo is a unique deposit with naturally carbonated healing water, suitable for the treatment of people with cardiovascular disease. The two localities in Nastan district remain unused for the time being.

\section{History}

The history of the development of the Devin's region as a treatment center, using its mineral waters can be traced back to the first century $\mathrm{AD}$, thus marking the beginning of the 20th century history of today's Bedenski Bani. Evidence of the exploitation of all thermal and other healing springs in the Devin region has been found during the period of Roman rule (I-IV century) [8]. In 1923, a large building was built in Bedenski Bani, which serves for the treatment of patients. 12,000 people a year passed through the bath for bathing. In the same year, the head of the Sanitary Resort Department, Dr. Kochankov, stated: "...there are no conditions for the development of a resort on the spot (Bedenski Bani). It turned out to be much more expedient to transfer the water to Devin, and open resorts there, for the purpose to develop a project and to determine the terrain... " [9]

\section{The development of the resort}

The modern development of the balneotherapy business in the municipality of Devin can be noted since 1969, when the construction of a heating pipeline from Bedenski Bani to 
Devin, a hot water tank in the town, a balneotherapy clinic and a hotel in the town of Devin began. The claims of the local people about the healing properties of the Beden mineral springs for the treatment of diseases of the musculoskeletal system, chronic skin diseases, urogenital, gynecological and other diseases have been confirmed by scientific research. It is realized that it is difficult to deploy a good spa treatment at the place of the spring, "mainly due to lack of appropriate living conditions" and therefore it was decided as a place for future development of the spa business in the municipality to be in the city, "where there is and can to create far more favorable conditions".

Calculations have been made by specialists regarding the temperature of the water, which at the springs is $76^{\circ} \mathrm{C}$, for each kilometer it drops by $1{ }^{\circ} \mathrm{C}$ or a general drop of $11-12^{\circ} \mathrm{C}$. This cooling does not pose any danger to its healing properties. At the first stage there were built a polyclinic and a hygienic bath, and during the second stage it was planned to have a sanatorium with 300 beds. In addition to a polyclinic and a hygienic bath, paraffin treatment, physiotherapy, electrotherapy, gyms and others have been built in the rehabilitation unit. [10]

The water from Bedenski Bani is characterized as hyperthermal - hydrocarbonate-sulfatesodium-calcium with free carbon dioxide content. It is used by drinking and bathing to treat diseases of the musculoskeletal system, stomach, gynecological diseases and more. It is planned that the town of Devin will develop as an integral part of the high-mountain resort-tourist complex "Orpheus" with balneological treatment. "The main thing will be the development of the resort business, which will make it a real pearl in this beautiful mountain." [11]

In 1972 the construction of the spa began, together with other important for the development of the economy, construction, education, resort and spa work in the town of Devin. The fact that "Devin ranks second in the country in terms of mineral water availability after Velingrad" gives hope. For the needs of the spa in the city, a series of drillings for mineral water have been carried out, and from one of them (B3) the water has been brought with a heat pipe and with it the procedures in the pool and for extension have been fed. Thus, the spa is supplied with two types of mineral water - from Bedenski Bani and from the Devin wells, which has a different composition for the pool, baths, showers and a modern drinking fountain.

A thermal reservoir was built and a heat pipeline was laid through the city to the spa. The spa itself is well furnished and equipped with modern equipment for those times, treatment rooms and procedures have been opened. At the same time, the construction of the Grebenets Hotel, a hotel complex, an extensive restaurant, a tavern and meeting rooms was completed. The spa and the hotel were officially opened on September 6, 1974. The opening of the two sites - the hotel and the spa, attracted the attention of the organizers of spa treatment and tourism and in the spring of 1975 a group of citizens of the Republic of Finland arrived for treatment and rest. Their shifts continue until late autumn. [12] In 1979, the development of Devin as a center for international tourism was determined. Its balneotherapy and climatic features make it suitable for the treatment of diseases of the musculoskeletal, nervous, digestive and urinary systems. The conditions in Devin are suitable for primary and secondary balneoprophylaxis in all cases, requiring general strengthening of the organism and recovery after suffering from the mentioned diseases. [13]

The sanatorium had 30 beds and the boarding beds reached up to 100 . There was a restaurant with 100 seats for the patients in the sanatorium and in the boarding house. The spa had a swimming pool (where the water temperature was $37^{\circ} \mathrm{C}$ ), two changing rooms 
and showers. Bathing for women and men took place in shifts. There were 10 baths for women and 10 for men, where the water temperature was $37-40^{\circ} \mathrm{C}$. The spa was opened all year round. In addition to the Bulgarian citizens, about 300 foreign citizens, mainly Finns, spent their holidays in the hotel "Grebenets" of Balkantourist (with 160 beds, with a restaurant and a bar). 14- and 21-day treatment shifts were organized for foreign guests. In order to develop the resort, it was planned to build a hotel-restaurant of "Balkantourist" with 400 beds, connected to the spa (started but unfinished. Nowadays it is part of the spa complex "Orpheus"); the expansion of the resort boarding house to 400-500 beds, a heating pipeline was built ( $800-1000 \mathrm{~m}$ ) for additional supply with mineral water, mainly from borehole № 3; construction of an outdoor mineral pool and a site for motor, air and solar procedures.

Treatment at this time was carried out by a good medical team. There were experienced nurses and rehabilitators. The treatment were carried out in well-equipped rooms, through electrotherapy, paraffin treatment, massages and water treatment with procedures in baths, extension and swimming in the pool with warm mineral water. There was a beautifully decorated mineral drinking water fountain for the treatment of intraabdominal diseases. Good opportunities have been created for examinations, services and treatment of the population of the city and the municipality, the people who came and need treatment from the interior of the country.

Nowadays, the continuation of the traditions is the SPA COMPLEX "ORPHEUS", which is located in its own park in the center of Devin. June 18, 2005 is the official opening of the complex. Even with the major renovation of the complex, an accessible architecture for people with reduced mobility is provided. Much attention is paid to the construction of infrastructure to support the work of the rehabilitation and rehabilitation program. SPA COMPLEX "ORPHEUS" consists of 2 sites: the 5-star SPA hotel "Orpheus" and "Specialized Hospital for Rehabilitation - Orpheus". The main activity is providing services for Bulgarian and foreign clients and patients. The complex itself has 210 rooms. "SHR - Orpheus" has issued a Permit for medical activities by the Minister of Health with subject of activity: Implementation of specialized hospital care including diagnosis and treatment of persons in need of physical therapy, motor and mental therapy, spa, climate - and thalassotherapy, as well as other medical activities duly authorized by the competent authorities.

There are 92 accommodation places with 1748 beds (Table 1) on the territory of the municipality Devin. 9 accommodation places $(9.8 \%)$ with 771 beds $(44.1 \%)$ of these are supplied with healing mineral water. These are mostly the hotels that provide the majority of employment in the municipality (Only Orpheus realized 53\% of all overnight stays for 2019), which means that mineral water has a great importance for the development of the municipality as an attractive tourist destination. 
Table 1 Accommodation places in the municipality of Devin total and with mineral water, up to date for 27 September 2020

\begin{tabular}{|c|c|c|c|c|c|}
\hline \multicolumn{3}{|c|}{$\begin{array}{l}\text { Total accommodation places } \\
\text { in Devin municipality }\end{array}$} & \multicolumn{3}{|c|}{$\begin{array}{l}\text { Accommodation places within mineral } \\
\text { water in Devin municipality }\end{array}$} \\
\hline Category & $\begin{array}{l}\text { Number } \\
\text { of objects }\end{array}$ & $\begin{array}{l}\text { Number of } \\
\text { beds }\end{array}$ & Category & $\begin{array}{l}\text { Number of } \\
\text { objects }\end{array}$ & $\begin{array}{l}\text { Number of } \\
\text { beds }\end{array}$ \\
\hline $1 *$ & 10 & 180 & $1 *$ & 0 & 0 \\
\hline $2 *$ & 58 & 581 & $2 *$ & 0 & 0 \\
\hline $3 *$ & 19 & 325 & $3 *$ & 4 & 109 \\
\hline $4 *$ & 3 & 250 & $4 *$ & 3 & 250 \\
\hline $5^{*}$ & 2 & 412 & $5 *$ & 2 & 412 \\
\hline Total & 92 & 1748 & Total & 9 & 771 \\
\hline
\end{tabular}

For the purposes of this analysis there are summarized data on tourist demand in the municipality of Devin by the National Statistical Institute of Bulgaria (Table. 2).

Table 2 Main indicators of tourist demand in the period 2007-2019

\begin{tabular}{|c|c|c|c|c|c|c|c|c|c|}
\hline \multirow[b]{2}{*}{ Year } & \multicolumn{3}{|c|}{ Overnights } & \multicolumn{3}{|c|}{ Tourists } & \multicolumn{3}{|c|}{$\begin{array}{l}\text { Income from overnight } \\
\text { stays - in thousants leva }\end{array}$} \\
\hline & Total & Bulgarians & Foreigners & Total & Bulgarians & Foreigners & Total & Bulgarians & Foreigners \\
\hline 2007 & 60084 & 51274 & 8810 & 26985 & 23730 & 3255 & 3823 & 3202 & 621 \\
\hline 2008 & 47722 & 39305 & 8417 & 20415 & 17857 & 2558 & 2280 & 1817 & 463 \\
\hline 2009 & 45154 & 39389 & 5765 & 19451 & 17217 & 2234 & 2101 & 1747 & 354 \\
\hline 2010 & 37417 & 32241 & 5176 & 17953 & 15918 & 2035 & 1797 & 1456 & 341 \\
\hline 2011 & 62141 & 53807 & 8334 & 28066 & 25597 & 2469 & 2307 & 1981 & 326 \\
\hline 2012 & 55143 & 47624 & 7519 & 25248 & 22359 & 2889 & 2243 & 1937 & 306 \\
\hline 2013 & 59559 & 52470 & 7089 & 27022 & 24203 & 2819 & 2696 & 2346 & 350 \\
\hline 2014 & 66495 & 58798 & 7697 & 31564 & 28181 & 3383 & 3011 & 2631 & 380 \\
\hline 2015 & 70412 & 62042 & 8370 & 35035 & 30920 & 4115 & 3017 & 2574 & 443 \\
\hline 2016 & 94600 & 82803 & 11797 & 47066 & 42096 & 4970 & 3683 & 3149 & 534 \\
\hline 2017 & 89993 & 78273 & 11720 & 45441 & 40846 & 4595 & 3685 & 3115 & 570 \\
\hline 2018 & 92276 & 81039 & 11237 & 46026 & 41137 & 4889 & 3969 & 3438 & 531 \\
\hline 2019 & 111670 & 97915 & 13755 & 53241 & 46723 & 6518 & 5136 & 4454 & 681 \\
\hline $2019-2018$ & $21.0 \%$ & $20.8 \%$ & $22.4 \%$ & $15.7 \%$ & $13.6 \%$ & $33.3 \%$ & $29.4 \%$ & $29.6 \%$ & $28.4 \%$ \\
\hline $2019-2007$ & $85.9 \%$ & $91.0 \%$ & $56.1 \%$ & $97.3 \%$ & $96.9 \%$ & $100.2 \%$ & $34.3 \%$ & $39.1 \%$ & $9.7 \%$ \\
\hline
\end{tabular}

For 2019 the realized overnights in the municipality of Devin represent $13.92 \%$ of the total for Smolyan district and $0.41 \%$ of the total for the country of Bulgaria, as the overnight stays are $17.08 \%$ of the total for Smolyan district and $0.65 \%$ of the total for the country. In the local market, the municipality of Devin realized $15.08 \%$ of the overnight stays and $17.19 \%$ of the persons for Smolyan district and respectively $1.01 \%$ of the overnight stays and $1.13 \%$ of the persons for the country. A total of 111,670 overnight stays were reported, $87.7 \%$ of which $(97,915)$ were from Bulgarians. 53,241 people spent the night, of which $87.8 \%(46,726)$ were Bulgarians.

In terms of attracting foreign tourists, the municipality of Devin is far from the average for the country, where $64.4 \%$ of all overnight stays are from foreigners, but it is close to the average for the district, where $80.9 \%$ of overnight stays are from Bulgarians. According to these indicators, the tendency of tourism in Smolyan district to have a greater weight on the domestic market than on the foreign market is strengthened. 


\section{CONCLUSION}

Nowadays, the goal of the tourism business should be the returning of the people to the natural healing factors that have been used since ancient times to the present day to heal the body. The issue of taking a person out of the everyday tense and stressful environment, containing various harmful substances, and sending him to a calm, ecologically clean and healthy environment is becoming more and more topical. This can be achieved by actively targeting the climatic and spa resorts with specific climatic characteristics - a high percentage of sunshine; low to missing fogs; air rich in light negative ions and phytoncides; natural thermal mineral waters, successfully applied for drinking, external, inhalation and other types of balneotherapy.

Tourism in the municipality of Devin has not yet reached its full potential, despite the existing prerequisites for its development such as natural resources, cultural heritage and built tourist infrastructure. Devin has a great past as a tourist destination, but at the moment there is still a lot of work to be done to establish it on the national and international map.

Attracting foreign tourists is extremely important for the stability of the sector - foreign tourists spend more money during the accommodation, food and additional activities, but have higher requirements for cleanliness, quality of service and quality of services offered in general. These are aspects that must be paid attention by all participants in the production of the tourist service.

The data must invariably be used in order to bring tourism back to its roots balneotherapy. The crisis caused by the corona virus COVID-19 only reinforces the trend that people will increasingly look for destinations that, in addition to safety, offer real benefits for body and soul.

COVID-19 will certainly cause many problems for some, but it will also be a great chance for others. It remains to be seen to what extent measures to limit the spread of the virus have harmed tourism globally, nationally and locally. Only those who adapt quickly to the changing environment and are willing to cooperate at different levels will be successful.

Certainly the municipality of Devin will be among the winning destinations, mostly because of the great conditions and individual benefits it can offer to tourists!

\section{REFERENCES}

[1] Vodenska, M., M. Assenova, 2011, Introduction into the Tourism, Matkom, Sofia

[2] Slaveykov, P., K. Naydenov, 2009, Economy of Tourism, University publishing house. St.Kliment Ohridski, Sofia

[3] Petrova, Z, S. Ganew, E. Petrowa-Dzheretto, 2019, Modern Guidelines in the Management of the Health System, PICS Ltd., Sofia

[4] Kotler, P., D.C. Jain, S. Maesincee, 2015, Marketing Moves. A New Approach to Profits, Growth and Renewal, East-West, Sofia

[5] Butler, R.W., 1980, The Concept of a Tourist Area Cycle of Evolution: Implications for Management of Resources, University of Western Ontario

[6] Marinov, V., 1997, The landscape as the core of the tourism product - consequences for tourism policy and planning. Environment - landscape and ecology. Theoretical and applied aspects, Bulletin'97. Union of Architects in Bulgaria, Sofia

[7] Marinov, V., V. Garnizov, S. Popov, G. Minasyan, M. Rusev, N. Boneva, P. Dikov, U. Spiridonova, P. tsvetanov, S. Motev, B. Mollov, P. Borisova, A. Yoveva, S. Lomeva, T. Gandova, 
1998, Challenges for Sustainable Development in Bulgaria, United Nations Development Program, Sofia

[8] Gerdzhikov, S, 2005, The Richness ot Bedan, Ekstrim

[9] Damyanov, N, 2014, newspaper. Vestnika, count.33, 1-7 august 2014

[10] Yurukov, I, 1969, magazine. Rhodope, count.3

[11] Zoinski, I, 1974, The Mountain of Devin, Medicine and physical education, Sofia

[12] Tashkov, D., 2016, The New Devin, Zea-print, Smolyan

[13] Nikiforov, N., G. Naydenov, 1982, Devin, Medicine and physical education, Sofia 